\title{
Finite element analysis of the Superbolt under dynamic loading
}

\author{
BV Nguyen Laurentian University, Canada \\ M Cai Laurentian University, Canada \\ K Challagulla Laurentian University, Canada
}

\begin{abstract}
As the depth of mining and underground construction increases, rock failure leading to seismic events and rockbursting is inevitable. Rockbursts can cause fatalities and/or injuries to workers, damage mine infrastructure and/or equipment and disrupt production. To minimise rockburst risk, design measures will be required. As an important line of defence, ground control support systems are used to prevent or minimise rockburst damage to excavations and enhance workplace safety. A new, patented dynamic rockbolt (the Superbolt) that integrates a reinforcement component (SDA) and a yielding component (paddle bolt) has been developed. The paddle bolt's shank can slide freely inside the SDA when the bolt is plastically stretched. If the epoxy resin is not properly mixed and the paddle anchor slides, the SDA acts as a secondary mechanical anchor and holds the paddle in place, allowing yielding of the paddle. This new technology allows a one-pass support system to be installed underground, which will result in significant saving in mining operations. In this paper, finite element models are developed to simulate the dynamic drop tests of the paddle Superbolt using Abaqus. The split-tube and continuous-tube drop tests are simulated, and the results from the numerical simulations are in reasonable agreement with the experimental results. A parametric study is performed based on various parameters (i.e. friction, geometry, material strength, etc.) to analyse the performance of the bolt. The results demonstrate that the quality of epoxy-resin mix, the strength and ductility of the bolt material and the corrugated pipe (SDA) influence the performance of the rockbolt. The parametric study improves understanding of the influence of various parameters on the performance of the Superbolt and aids in improving the design of this ground support technology.
\end{abstract}

Keywords: finite element analysis, rockbolt, Superbolt, paddle bolt, dynamic drop test

\section{Introduction}

With ore deposits depleting at shallow depths, there is an increasing need to mine at deeper levels. However, as the depth of mining and underground construction increases, rock failure leading to seismic events and rockbursts is inevitable. To minimise rockburst risk, design measures will be required. Ground control support systems are an important line of defence to prevent or minimise rockburst damage to excavation and enhance workplace safety (Cai 2013; Kaiser \& Cai 2012; Kaiser et al. 1992; Ortlepp 1992; Zhang et al. 2012).

A ground support system has three functions (Kaiser et al. 1996):

- Reinforce (strengthen and assist the rock mass to support itself).

- Retain (contain loosened rock pieces near the surface).

- Hold (arrest and stabilise the seismic-induced rockfall).

Ground support is effective in stabilising rock masses, but installation can be time-consuming. Conventional installation of a rock support system is a two-pass process; conventional rockbolts and mesh are installed first upon tunnel excavation, and dynamic rockbolts are installed at a later stage. A new type of patented 
dynamic rockbolt (Superbolt; Cai et al. 2019) allows a one-pass support system to be installed underground, which can result in significant savings in mining operations.

\subsection{Superbolt}

The Superbolt technology integrates a reinforcement component, which will help strengthen and assist the rock mass, and a yielding component to arrest and stabilise the seismic-induced rockfall. The yielding bolt can be in the form of the modified cone bolt (Cai \& Champaigne 2012) or the paddle bolt (or Versa-bolt), shown in Figure 1. The paddle Superbolt has a variable-length $20 \mathrm{~mm}$ diameter steel bar with four-paddle anchorage inside a roughened steel pipe (SDA). If a rockburst occurs, the plate and mesh will plastically stretch the bolt and slide freely inside the SDA. If, for some reason, the epoxy resin is not properly mixed and the anchor slides, the SDA acts as a secondary mechanical anchor and holds the bolt in place, allowing yielding of the rockbolt.

To further prove and improve the performance of the rockbolt, design modification and testing is required. However, laboratory- and field-testing of a new product is time-consuming and costly. To complete one design modification, several iterations of prototype manufacturing and testing are required. Hence, computer-aided product design and testing is required to reduce both the length of the product development cycle and the costs.

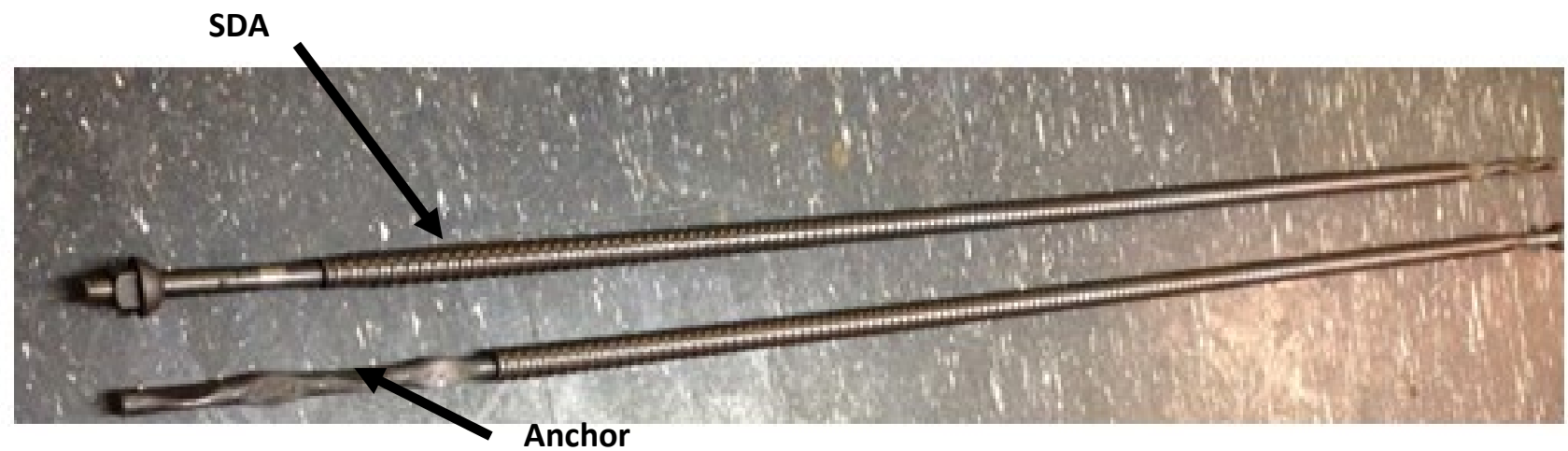

Figure 1 A paddle Superbolt

\section{$1.2 \quad$ Testing methods}

Many testing methods (Li et al. 2014) are available to evaluate the performance of rockbolts, such as the static pull test and shear block test. Due to the dynamic nature of rockburst, the continuous-tube dynamic drop test and split-tube dynamic drop test are used to evaluate the dynamic performance of the rockbolt.

\subsubsection{Continuous-tube dynamic drop test}

The continuous-tube dynamic drop test is used to evaluate energy-absorbing capacities of rockbolts (Figure 2). A rockbolt is encapsulated in a fixed thick-walled steel pipe with the use of grout-resin or cement. A mass freely falls onto a plate, which loads the rockbolt dynamically at a predetermined impact energy. Monitoring systems are used to measure load and displacements at both ends of the rockbolt so that loads and strains can be calculated. 


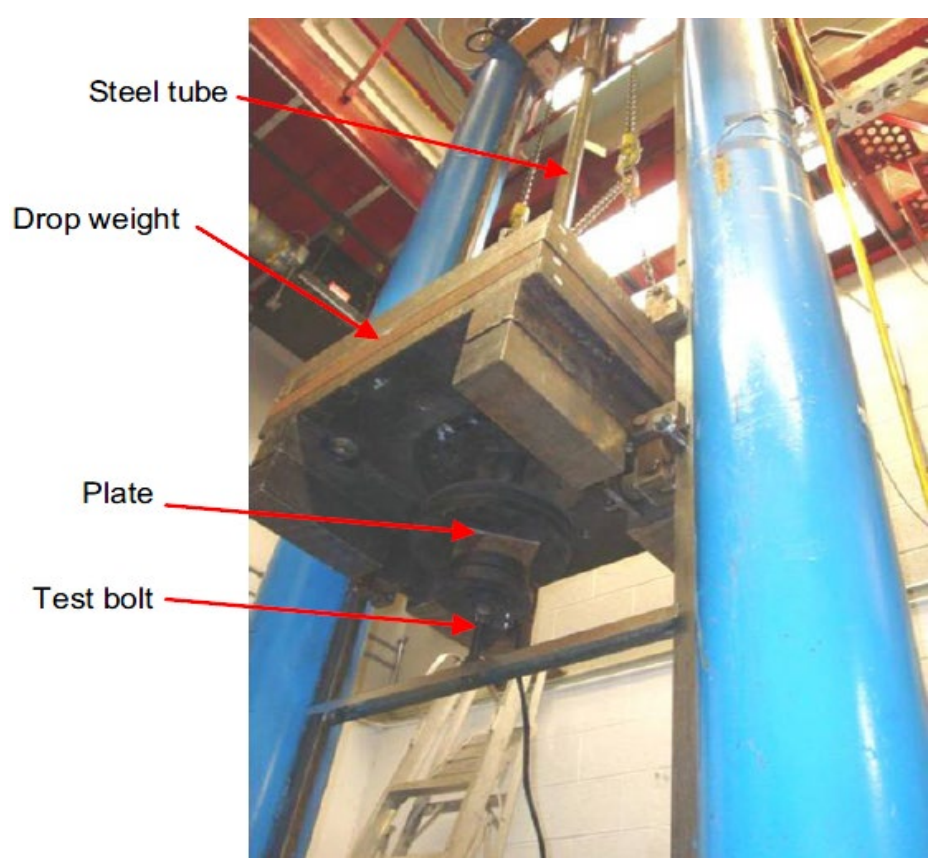

Figure 2 Drop test facility for rockbolt testing at CANMET, Canada

\subsubsection{Split-tube dynamic drop test}

The split-tube dynamic drop test is similar to the continuous-tube dynamic drop test (Figure 3). A split is cut through the outer thick wall of the steel pipe, and a stopper is then welded onto the outer pipe. A weight free falls onto the stopper instead of onto the plate to focus the yielding in the shank of the rockbolt. The split-tube dynamic drop test is used to evaluate energy-absorbing capacities of rockbolts indirectly. Monitoring systems are used to measure loads and displacements at both ends of the rockbolt so that loads and strains can be calculated.

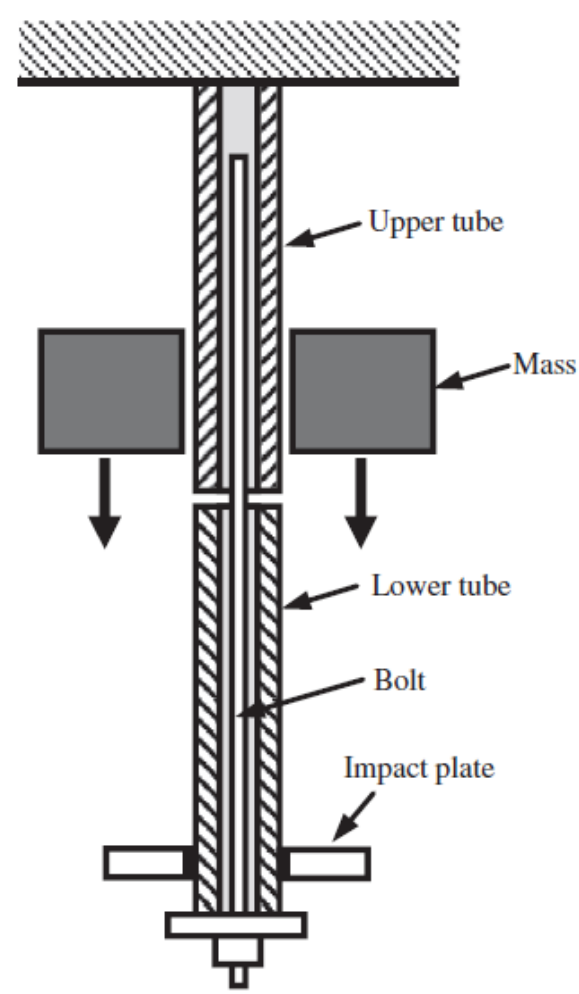

Figure 3 Mass free-fall split-tube test (Li et al. 2014, p. 5) 


\section{$2 \quad$ Modelling methodology}

Details of the laboratory static and dynamic test results are reported in Cai et al. (2019). Three experiment samples under impact energies of 30, 40 and $45 \mathrm{~kJ}$ were selected to model with a finite element analysis. All sample paddle bolt dimensions were similar, so an average was taken to represent all three samples to keep dimensions constant for all impact load tests. Two axisymmetric finite element models were created using the commercially available finite element software Abaqus. The finite element model of the split-tube test included a stopper and split in the outer pipe and resin. The continuous-tube dynamic drop test did not include the split and stopper in order to allow the drop weight to hit the plate directly. The model has six main components:

- A paddle bolt with a plate.

- Resin bonding between the paddle bolt and pipe.

- SDA.

- Surrounding pipe with/without stopper.

- Drop weight.

- Interfaces between the bolt, resin and SDA.

The paddle bolt in the SDA and the complete setup is fully encapsulated in resin inside a steel pipe. The drop mass changes depending on the impact energy (Equation 1), whereas the drop height and gravity are kept constant. Figure 4(a) shows the split-tube test, and Figure 4(b) shows the continuous-tube dynamic drop test finite element models. For clarity, the fine meshes are not shown in the figures.

$$
K E=m g h
$$

where:

$$
\begin{aligned}
K E & =\operatorname{kinetic} \text { energy }(\mathrm{J}) . \\
m & =\operatorname{mass}(\mathrm{kg}) . \\
g & =\operatorname{gravity}\left(\mathrm{m} / \mathrm{s}^{2}\right) . \\
h & =\operatorname{height}(\mathrm{m}) .
\end{aligned}
$$

The following assumptions are considered to simplify the model:

- The rockbolt has no threads.

- There is no head nut for the rockbolt.

- The resin-pipe interface is assumed to be fixed together.

- The SDA-resin interface is assumed to be fixed together.

- The friction interface is assumed for the bolt-resin interface.

- The friction interface is assumed for the bolt-SDA interface.

- The paddle anchors are ellipsoid. 


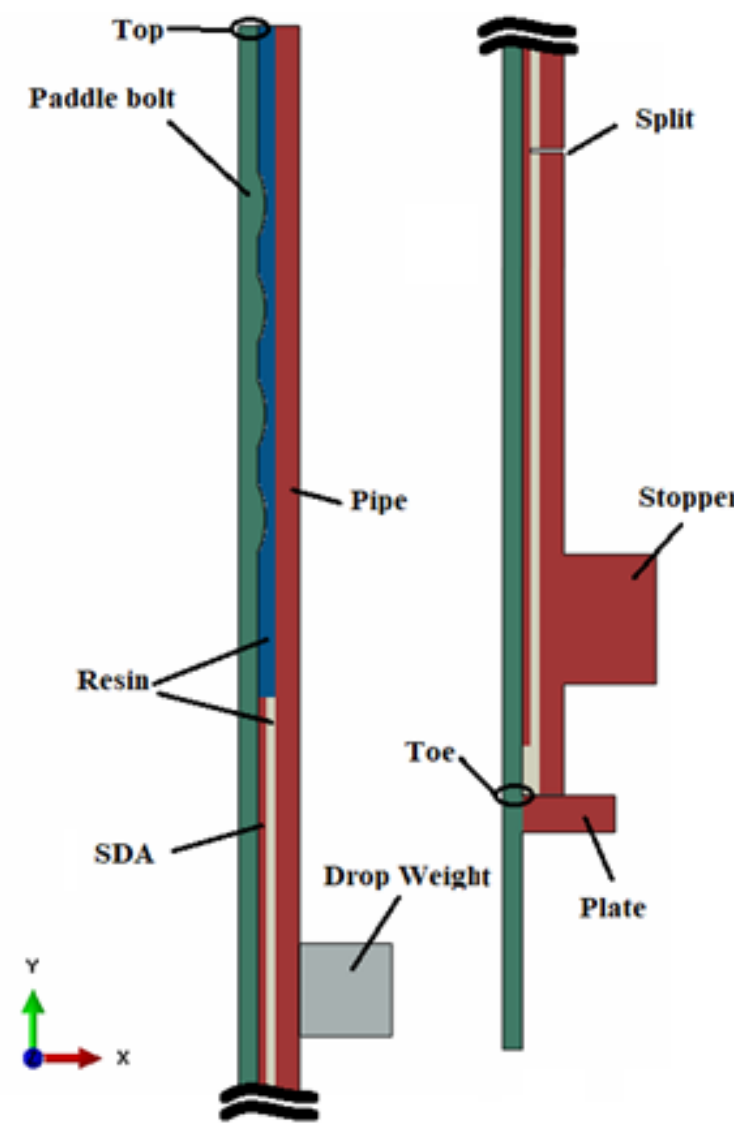

(a)

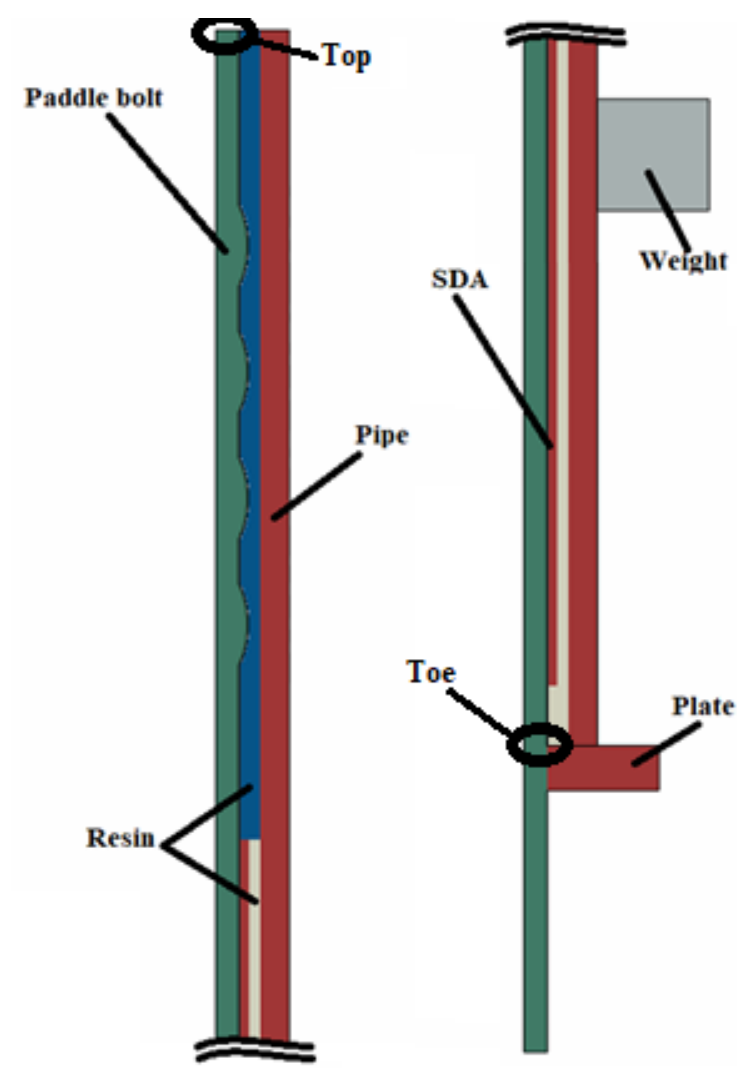

(b)

Figure 4 (a) Schematic of the axisymmetric split-tube dynamic drop test model; (b) Continuous-tube dynamic drop test model. The illustration is a sectional view and is not to scale

\subsection{Finite element model and material properties}

Dynamic explicit analysis in Abaqus was used to simulate the split-tube and continuous-tube dynamic drop tests. Taking into consideration the computation time for an explicit analysis, axisymmetric stress quad (CAX4R) element models were used to minimise the simulation time.

\subsection{Material properties}

For initial models, the material properties were either measured through laboratory testing or obtained from the literature (Nguyen et al. 2018) to best represent each model component. The three main components of concern were the encapsulate resin, SDA and the rockbolt.

To represent the rockbolt, the model needed to represent pre- and post-failure. The steel's (C1055) tensile and compressive behaviours are the same; thus, the selection of an appropriate material model is based on elasticity, plasticity and ductile damage consideration. Experiments were conducted to determine the deformation behaviour of the steel. The force-displacement curve obtained from the experiments was converted into a true-stress-true-strain curve for input into Abaqus.

The SDA can have an influence on the performance of the rockbolt when considering elasticity, plasticity and ductile damage. Experiments were conducted on the pipe material to obtain its yield and ultimate strength. The encapsulated resin is difficult to represent because of its plastic softening behaviour; nevertheless, laboratory experiments were conducted to determine the resin behaviour. It was found that the behaviour of the resin can be captured using the concrete damage plasticity model (Cicekli et al. 2012). Because the outer pipe, plate, and stopper do not affect the performance of the bolt, it was given the same 
material properties as the SDA with an elastic-plastic property. The drop weight material is not important; hence, general steel properties are used. The drop weight is elastic, with a varying density to accommodate the different impact energies.

\subsection{Interaction properties}

Using CAX4R elements requires surface-to-surface contact to be used. Two surface contacts are considered between the bolt head and resin as well as between the bolt shank and SDA. The coefficient of friction affects the contact behaviours of the paddle bolt's shank-to-SDA interface and the paddle-to-resin interface. Because the paddle bolt is not supposed to slide, a coefficient of friction was selected so that the top of the paddle bolt did not slide significantly, and a coefficient of friction for the interface of the shankto-SDA can be frictionless since there is clearance between the shank and SDA.

\section{$3 \quad$ Input data}

Figure 5 shows the converted nominal stress-strain curve from laboratory testing of tensile samples of the rockbolt material. This was then converted into a true stress-true strain curve for Abaqus. Table 1 presents the material properties used for each component of the simulation model.

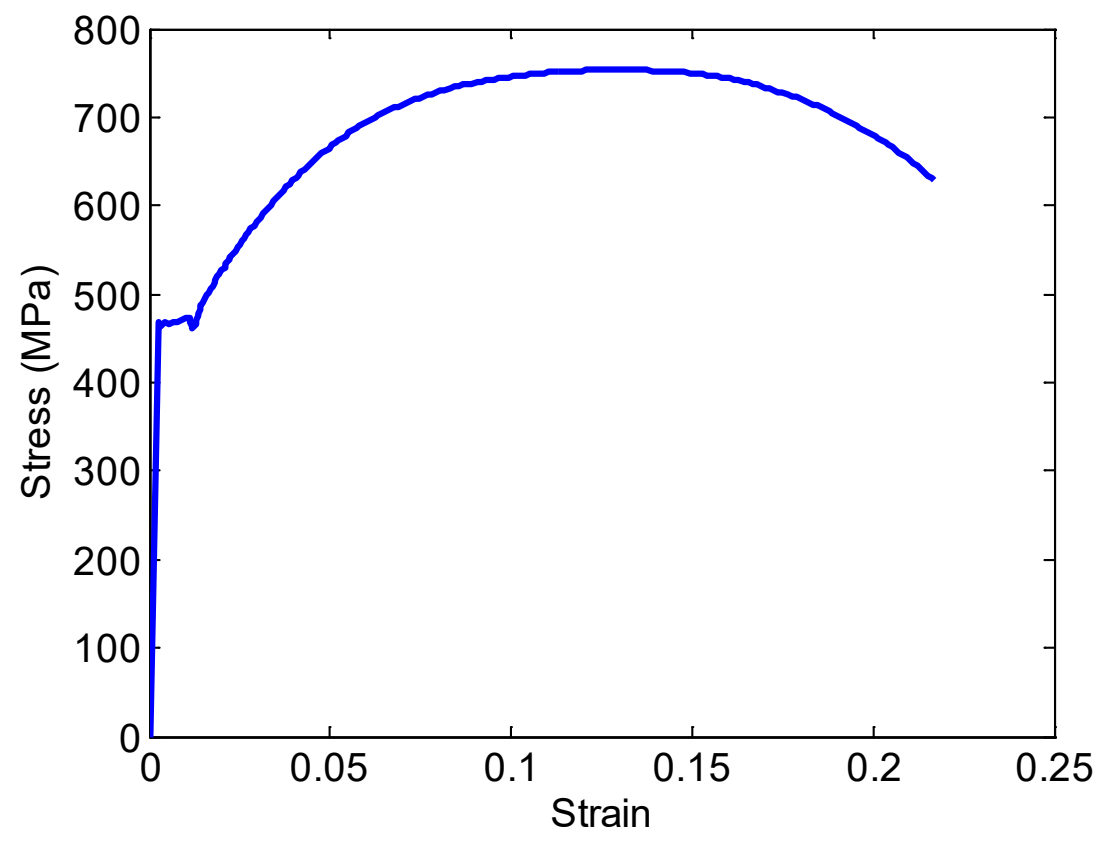

Figure 5 Stress-strain curve of C1055 steel obtained from laboratory test

Table 1 Material properties from experiments and literature

\begin{tabular}{lllllll}
\hline Component & Material & $\begin{array}{l}\text { Young's } \\
\text { modulus } \\
(\mathrm{GPa})\end{array}$ & $\begin{array}{l}\text { Poisson's } \\
\text { ratio }\end{array}$ & $\begin{array}{l}\text { Density } \\
\left(\mathbf{k g} / \mathbf{m}^{3}\right)\end{array}$ & $\begin{array}{l}\text { Yield } \\
\text { strength } \\
(\mathrm{MPa})\end{array}$ & $\begin{array}{l}\text { Ultimate } \\
\text { strength } \\
\text { (MPa) }\end{array}$ \\
\hline Paddle bolt & C1055 & 200 & 0.3 & 7,500 & 490 & 753 \\
SDA & Steel & 210 & 0.3 & $*$ & $24(\mathrm{C}), 1.8(\mathrm{~T})$ & $32(\mathrm{C}), 1.8(\mathrm{~T})$ \\
Resin & Faslok & $10-25$ & 0.15 & 2,050 & - & - \\
Weight & Steel & 210 & 0.3 & 7,500 & $550-650$ & $650-850$ \\
\hline
\end{tabular}

*Depending on the test and the geometry of the weight, the density is calculated to achieve 30,40 and $45 \mathrm{~kJ}$ impact energy. Note: $\mathrm{C}=$ compressive, $\mathrm{T}=$ tensile 


\section{$4 \quad$ Simulation results}

\section{1 $30 \mathrm{~kJ}$ split-tube dynamic drop test}

The simulation results from an axisymmetric model using the general parameters given above were compared with the $30 \mathrm{~kJ}$ laboratory test results and showed satisfactory results. Figure 6 shows the top (a) and the toe (b) displacements of the paddle bolt for three drops. The calibrated model represents the first drop well, but for the second drop the paddle bolt did not slide as much in the numerical model. The third drop is not shown because the paddle bolt failed in both the experiment and the simulation. Figure 7 shows the stress distribution after the first drop. This calibration is considered adequate because the top and toe displacements in the first drop were reasonable and the bolt fractured on the third drop. These parameters were used in the $40 \mathrm{~kJ}$ and $45 \mathrm{~kJ}$ drop test simulations.
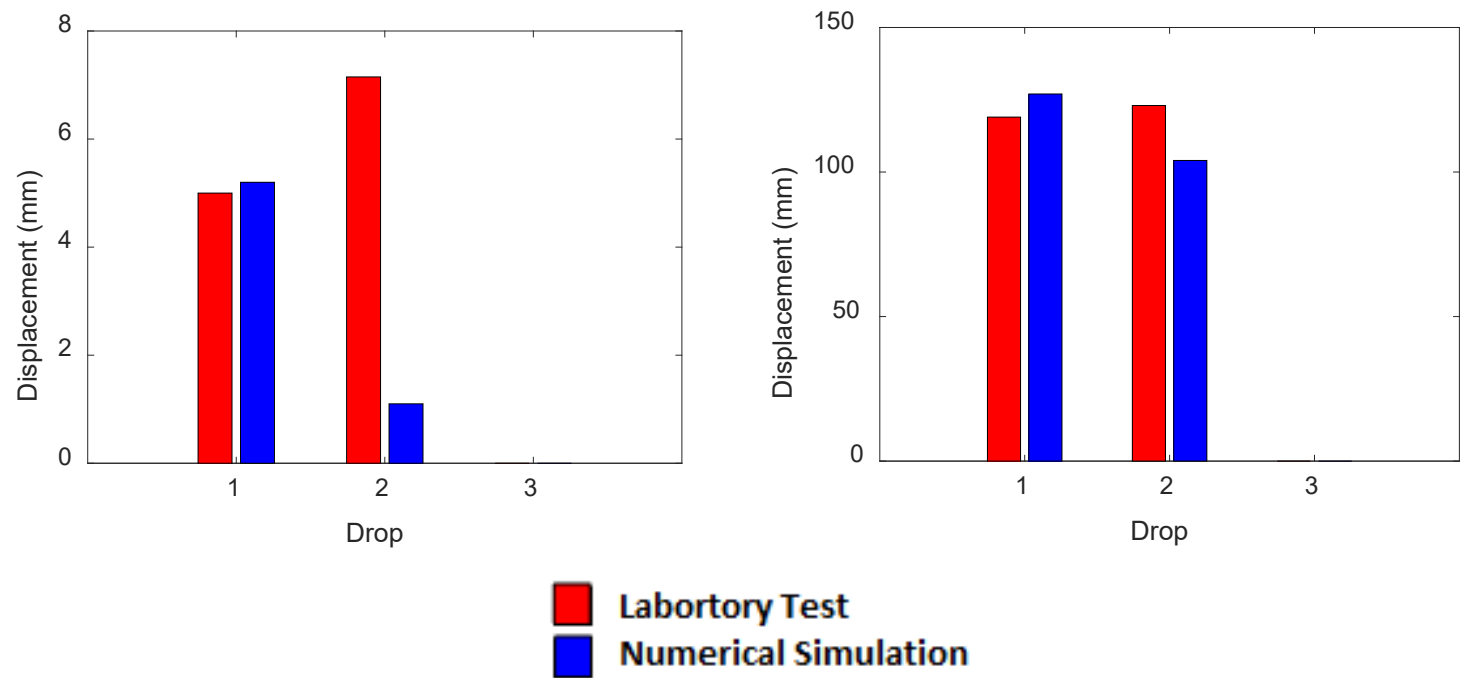

(a)

(b)

Figure 6 The calibrated $30 \mathrm{~kJ}$ split-tube dynamic drop test for (a) top and (b) toe displacement of the bolt
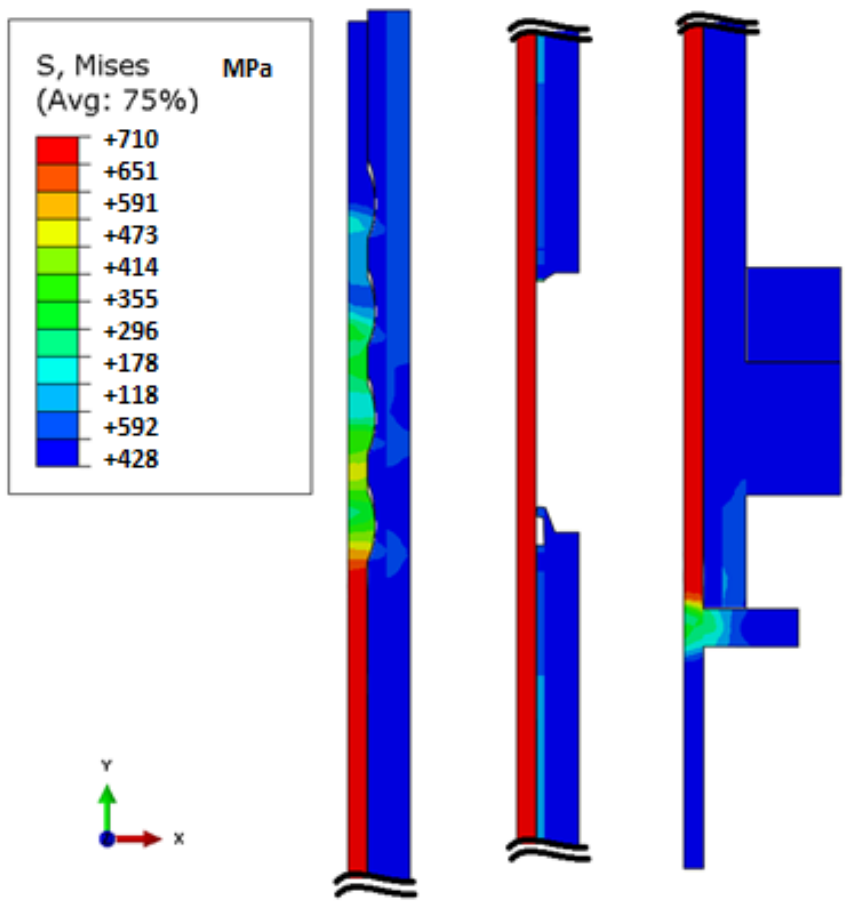

Figure 7 von Mises stress distribution of the $30 \mathrm{~kJ}$ split-tube dynamic drop test 


\section{$4.2 \quad 40 \mathrm{~kJ}$ split-tube dynamic drop test}

Using the same parameters from the $30 \mathrm{~kJ}$ input energy model, the $40 \mathrm{~kJ}$ drop test simulation results were not as favourable (Figure 8). The $40 \mathrm{~kJ}$ laboratory drop test results show that the paddle bolt slipped. It was hypothesised that the resin was improperly mixed; thus, the stiffness and strength (proportional to stiffness) of the resin were decreased to represent a weaker mix while keeping other parameters unchanged. Figure 9 shows that a weaker resin allowed the paddle bolt to slide. In this case, the paddle bolt fractured on the second drop.

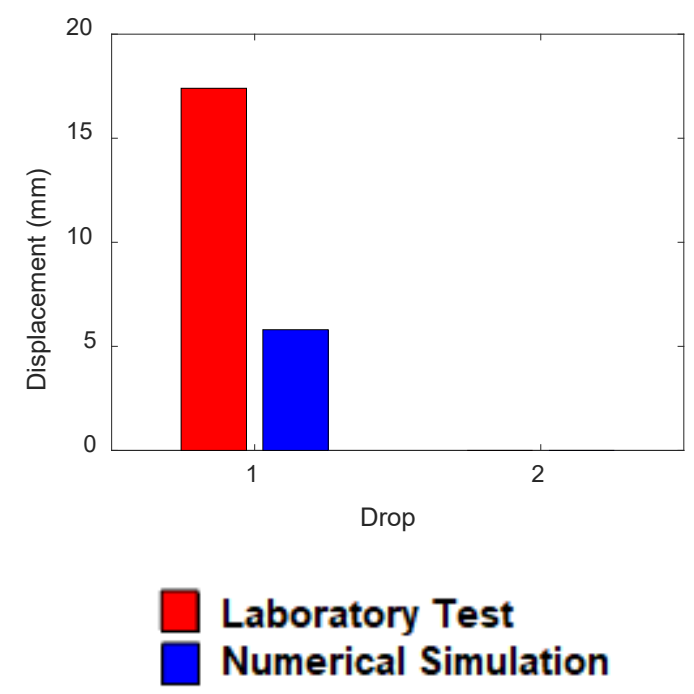

Figure 8 The initial calibrated (resin Young's modulus $=25 \mathrm{GPa}$ ) $40 \mathrm{~kJ}$ split-tube dynamic drop test results for top
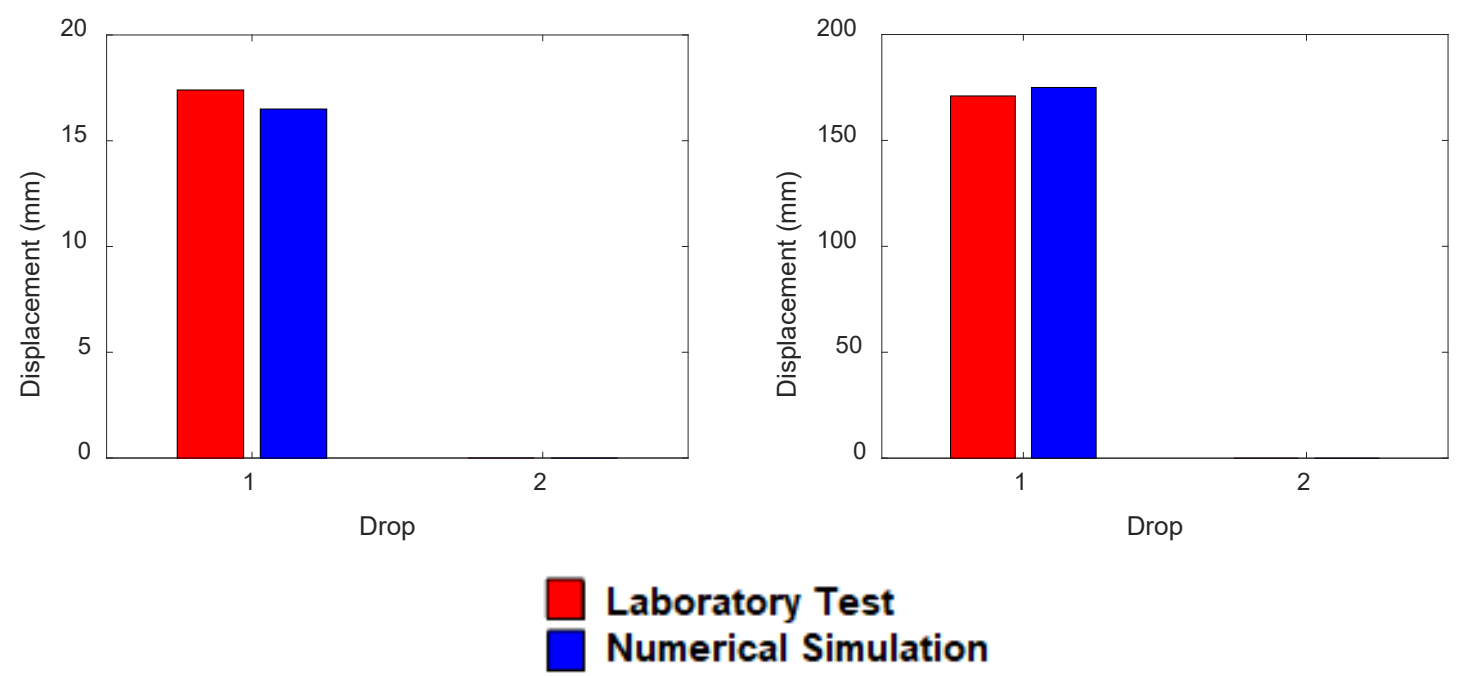

(a)

(b)

Figure 9 The final calibrated (resin Young's modulus = $10 \mathrm{GPa}$ ) $40 \mathrm{~kJ}$ split-tube dynamic drop test results for (a) top and (b) toe displacements of the bolt

\section{3 $45 \mathrm{~kJ}$ split-tube dynamic drop test}

Using the same parameters as the $30 \mathrm{~kJ}$ split-tube dynamic drop test, the simulation results show that the $45 \mathrm{~kJ}$ results are favourable, indicating that there was little bolt sliding upon dynamic loading. As shown in Figure 10, the bolt did not survive the second drop. 

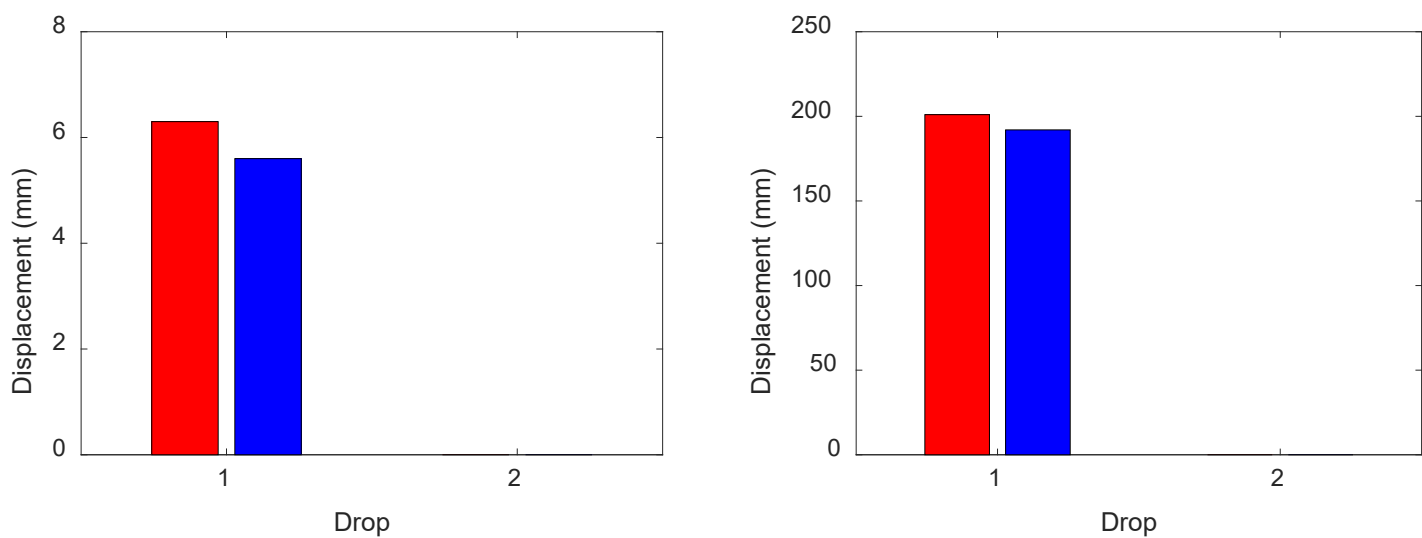

\section{Laboratory Test \\ Numerical Simulation}

(a)

(b)

Figure $1045 \mathrm{~kJ}$ split-tube dynamic drop test results for (a) top and (b) toe displacements of the bolt

\section{$4.4 \quad 30 \mathrm{~kJ}$ continuous-tube dynamic drop test}

The final calibrated parameters from the split-tube drop test were used for the continuous-tube dynamic drop test. Figure 11 compares the split-tube and the continuous-tube drop test simulation results. It is shown that in the first drop the top displaced almost the same amounts in both configurations but the toe displaced slightly more for the continuous-tube configuration. The bolt fractured on the second drop in the continuous-tube configuration while the spit-tube test fractured on the third drop. There was also a difference in where the fracture occurred. The split-tube loading led to fracture in the shank while the continuous-tube loading led to fracture near the plate (Figure 12).
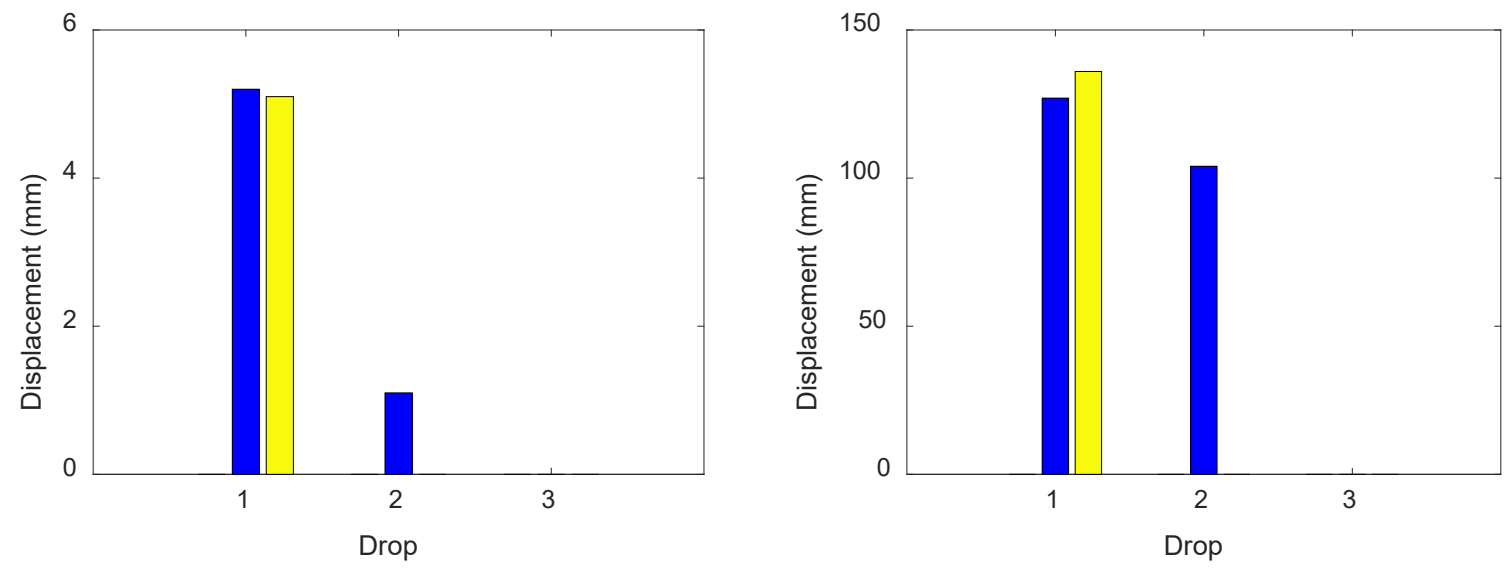

split-tube

continuous-tube

(a)

(b)

Figure $1130 \mathrm{~kJ}$ split-tube versus continuous-tube dynamic drop test results for (a) top and (b) toe displacements of the bolt 

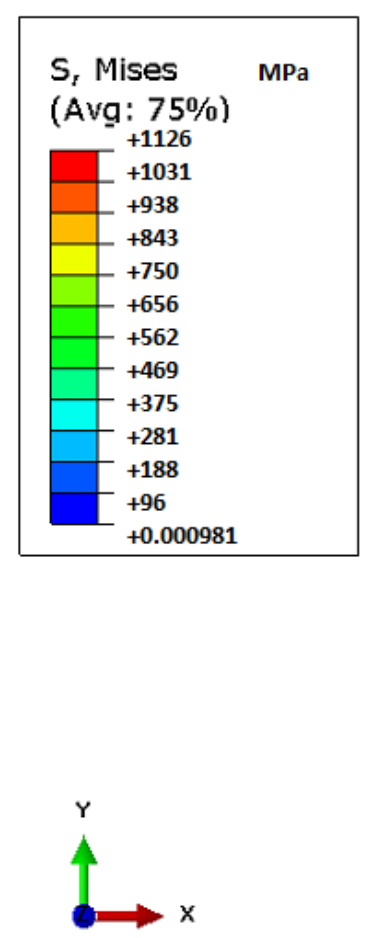

(a)
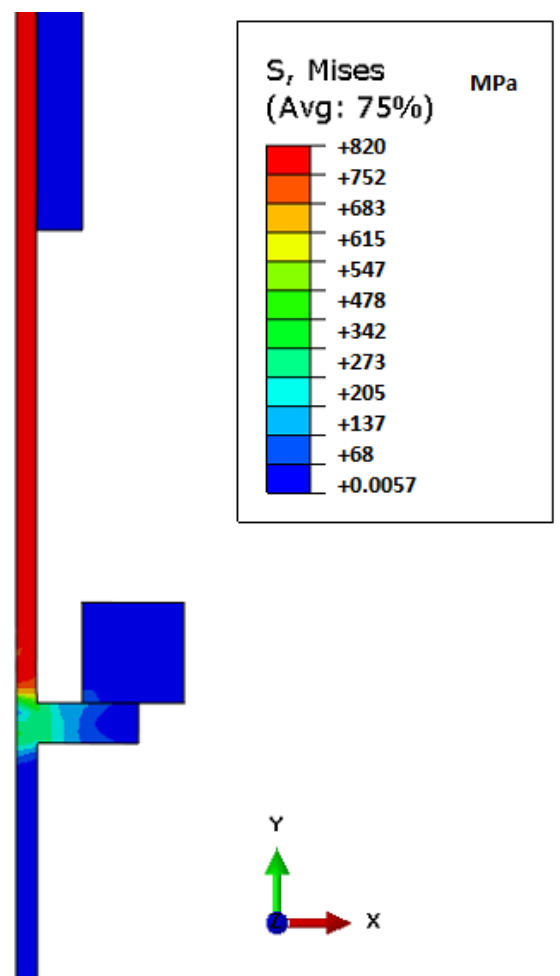

(b)

Figure 12 (a) von Mises stress of the $30 \mathrm{~kJ}$ continuous-tube dynamic drop prior to fracture and (b) after fracture

\subsection{SDA influence}

With the final calibrated parameters, the SDA plasticity (maximum plastic straining) was modified to see its effect on the modelled paddle Superbolt performance. Figure 13 shows that changing the plasticity of the SDA material can help the bolt absorb more energy. The red line shows the toe displacement using the calibrated parameters of the $30 \mathrm{~kJ}$ split-tube test with varying strains of the SDA material. The blue line shows the toe displacement with varying strains of the SDA material. Thus, a ductile and strong SDA can help the bolt to displace less at the toe. Changing the SDA parameters had little to no influence on the top displacement.

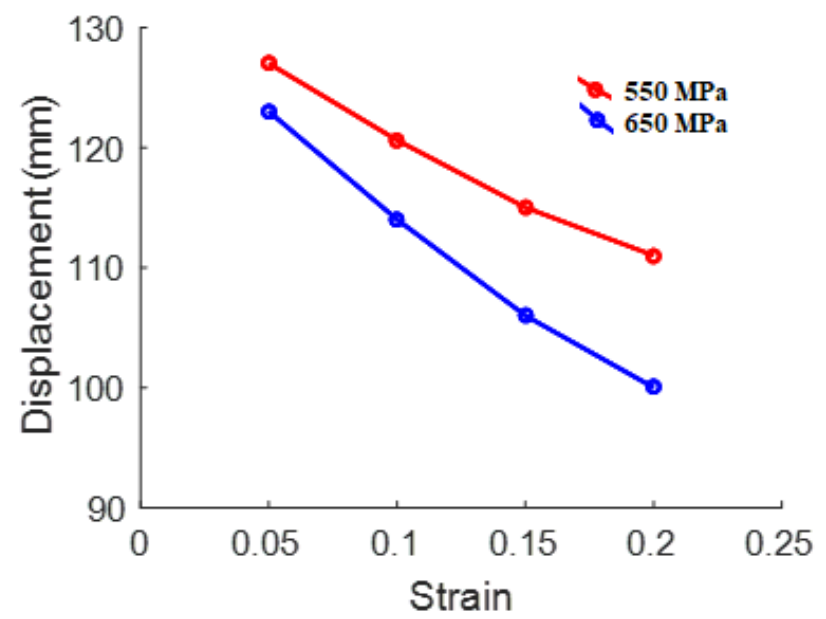

Figure 13 Influence of SDA plasticity on bolt toe displacement $(30 \mathrm{~kJ}$ input energy, split-tube configuration). Red is the yield strength of $550 \mathrm{MPa}$ and ultimate strength of $650 \mathrm{MPa}$, and blue is yield strength of $650 \mathrm{MPa}$ and ultimate strength of $850 \mathrm{MPa}$ 


\subsection{Anchor influence}

A study was conducted to investigate the effect of the number of paddles on the modelled anchorage capacity. The original design of the paddle Superbolt has four cold-pressed paddles. Figure 14 shows top displacement at $30 \mathrm{~kJ}$ impact energy in the split-tube configuration. The top displacements for three and four paddles were almost the same. However, reducing the number of paddles to two, more than doubled the amount of displacement at the top. Hence, for full capacity anchorage without sliding, at least three paddles are needed.

It is shown that the parameters used best represent the 30 and $45 \mathrm{~kJ}$ tests, but a weaker resin was needed to represent the $40 \mathrm{~kJ}$ test. A parametric study was conducted to study the performance of the bolt by varying the rockbolt strength, SDA strength, geometry of the paddle bolt, the resin strength and the coefficients of friction between the bolt-resin and bolt-SDA interfaces. The drop test simulation results showed that the rockbolt material strength influences the toe displacement and that increasing the strength of the rockbolt reduces displacement at the toe. The resin properties influence the top displacement of the bolt. Reducing the Young's modulus of the resin grout can lead to sliding of the bolt until it hits the SDA, demonstrating the importance of proper resin mixing to ensure performance of the paddle Superbolt. SDA ductility helps to reduce toe displacement. Reduction of one paddle will have little influence on the overall performance of the bolt. Detailed results of the parametric study cannot be reported in this paper due to length limitations but will be reported in future publications.

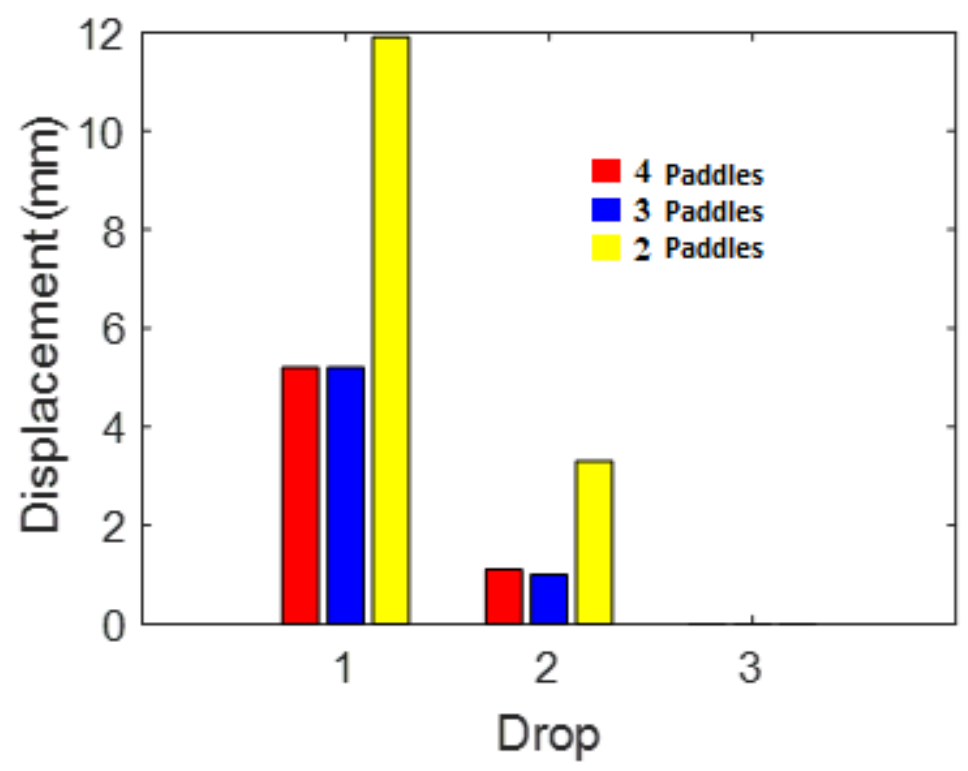

Figure 14 The calibrated $30 \mathrm{~kJ}$ split-tube dynamic drop, varying the number of anchors

\section{Conclusion}

The dynamic drop test results of the paddle Superbolt were simulated using an explicit finite element models tool. The modelling results agree well with the laboratory test results, indicating that the finite element models tool can be used to simulate complex bolt deformation and failure behaviours. Further development of the bolt can be assisted with the use of a numerical approach to reduce both the length and cost of the product development cycle. The paddle Superbolt has the desired rock-reinforcement and yielding-support capacities. Its use in burst-prone underground mines can be expected to increase workplace safety and enhance productivity.

\section{Acknowledgement}

Financial support from the Natural Sciences and Engineering Research Council (NSERC, CRDPJ 461108 - 13) of Canada and Mansour Mining Technologies Inc. for this work is gratefully acknowledged. 


\section{References}

Cai, M 2013, 'Principles of rock support in burst-prone ground', Tunnelling and Underground Space Technology, vol. 36, pp. 46-46.

Cai, M \& Champaigne, D 2012, 'Influence of bolt-grout bonding on MCB conebolt performance', International Journal of Rock Mechanics and Mining Sciences, vol. 49, pp. 165-175.

Cai, M, Champaigne, D, Coulombe, JG \& Challagulla, K 2019, 'Development of two new rockbolts for safe and rapid tunneling in burst-prone grounds', manuscript submitted for publication.

Cicekli, U, Voyiadjis, GZ \& Abu al-rub, RK 2012, 'A plasticity and anisotropic damage model for plain concrete', International Journal of Plasticity, vol. 23, no. 10-11, pp. 1874-1900.

Kaiser, PK \& Cai, M 2012, 'Design of rock support system under rockburst condition', Journal of Rock Mechanics and Geotechnical Engineering, vol. 4, no. 3, pp. 215-227.

Kaiser, PK, Tannant, DD \& McCreath, DR 1996, Canadian Rockburst Support Handbook, Laurentian University, Sudbury.

Kaiser, PK, Tannant, DD, McCreath, DR \& Jesenak, P 1992, 'Rockburst damage assessment procedure', in PK Kaiser \& DD McCreath (eds), Rock Support in Mining and Underground Construction, A.A. Balkema, Rotterdam, pp. 639-647.

Li, CC, Stjern, G \& Myrvang, A 2014, A Review on the Performance of Conventional and Energy-absorbing Rockbolts, Chinese Academy of Sciences, Beijing.

Nguyen, B, Cai, M \& Challagulla, K 2018, 'Finite element analysis of modified conebolt under static and dynamic loadings', Proceedings of the Canadian Society for Mechanical Engineering International Congress 2018, Canadian Society for Mechanical Engineering, Ottawa.

Ortlepp, WD 1992, 'The design of support for the containment of rockburst damage in tunnels-an engineering approach', in PK Kaiser \& DR McCreath (eds), Rock Support in Mining and Underground Construction, A.A. Balkema, Rotterdam, pp. 593-609.

Zhang, C, Feng, XT, Zhou, H, Qiu, S \& Wu, W 2012, 'Case histories of four extremely intense rockbursts in deep tunnels', Rock Mechanics and Rock Engineering, vol. 45, no. 3, pp. 275-288. 